\title{
Trophic Evolution of Southern Green Stink Bugs (Nezara viridula l.) in Western Part of Romania
}

\author{
Ioana GROZEA ${ }^{1 *}$, Ana Maria VIRTEIU ${ }^{1}$, Ramona STEF ${ }^{1}$, Alin CARABET ${ }^{1}$, Levente MOLNAR ${ }^{1}$, Teodora \\ FLORIAN $^{2}$ and Mihai VLAD ${ }^{1}$ \\ ${ }^{1}$ Department of Biology and Plant Protection, Banat's University of Agricultural Sciences and \\ Veterinary Medicine "King Michael I of Romania" Timisoara, Romania. \\ ${ }^{2}$ Department of Environment and Plant Protection, University of Agricultural Science and Medicine \\ Veterinary Cluj Napoca \\ *)corresponding author, e-mail: ioana_entomol@yahoo.com
}

BulletinUASVM Horticulture 72(2) / 2015

Print ISSN 1843-5254, Electronic ISSN 1843-5394

DOI:10.15835/buasvmcn-hort:11391

\begin{abstract}
Nezara viridula L. (Hemiptera:Pentatomidae) is a relative a invasive species, highly poliphagous, species of solanaceous, legumes, cruciferous, malvaceous, grasses and other plants are affected. Considering that the insect which make the subject of this scientifically paper is a species detected in our country but unregistered and unlocalized as a dangerous species we want to bring to attention potential spread and adaptation to new plant species, especially legumes and ornamental plants. Observations were made in Timis county in the western part of Romania (Timis), during the years 2013 and 2014. It was taken under observation by three types of plants (tomato crop, green space and fruit tree plantation). The observations on plants have shown that $N$. viridula affected all four varieties of tomatoes, especially on fruits, both green and mature stage. In green space only adults and nymphs was observed on follow ornamental plants: Syringa vulgaris, Lonicera japonica, Hibiscus sp. and Magnolia liliiflora. Comparative study between Prunus persica and Prunus persica var. nucipersica made in fruit tree plantation has revealed that insect affected only the last one. $N$. viridula is a dangerous species for Romania with high expansion potential on new host plant and new surfaces.
\end{abstract}

Keywords: host plants, invasive insect, Nezara viridula, polyphagous

\section{INTRODUCTION}

The southern green stink bugs (Nezara viridula L.) is a relative new invasive species in Europe, being native to warmer areas, respectively African and Mediteranean areas. It is considered one of the most important pentatomid insect pests in the world (Todd, 1989).

The pest is a cosmopolitan species living in tropical and subtropical regions of Africa, America, Australia, Europe and Asia (Squitier, 1997; Capinera, 2001; Musolin, 2005; Panizzi, 2008; Yukava, 2007).

$N$. viridula has long attracted attention not only as a serious pest of numerous agricultural crops, but also as a species expanding its range in many parts of the world (Musolin, 2012).
The southern green stink bug has piercingsucking mouthparts. All plant parts are likely to be fed upon, but growing shoots and developing fruit are preferred (Squitier, 1997).

The degree of damage depends on the developmental stage of the plant and when it is pierced by stink bugs. Damage in vegetable can result in immature fruit becoming deformed as they develop (Lye et al., 1988).

\section{MATERIALS AND METHODS}

The research has been carried out in Timisoara (Timis county) in the western part of Romania, during the years 2013 and 2014. Observations were made both in experimental tomato field of 
previously held and also in orchards and green spaces in the locality.

On tomatoes were considered four varieties such as Oxheart, Costoluto Fiorentino, Sweet Baby and Black Cherry (Fig.1), the last ones being cherry variety. They were organized in three rehearsals.

Given the potential food species (plants of over 30 botanical families) and the only one alert reference to the country (in 2010, in Timisoara) our study was expanded in terms of area and plant surfaces.

During the vegetation period were made observations on plants (two direct readings per month from June to October). Were taken into consideration both mature (adult) and immature (nymph, larva) forms of Nezara viridula.

\section{RESULTS AND DISCUSSION}

Following observations from 2013 and 2014 can be seen as the larvae have reached a high level of numerical population in both years study especially in the experimental plots with tomatoes.

High values were even recorded especially in 2014, with an average of $\overline{\mathbf{x}}=100.25$ individualslarvae/plant/read. In 2013 there were high values also, respectively of $\overline{\mathbf{X}}=64.08$ individuals/plant/ read (Fig. 2).

Adults and nymphs were also present on the plants, but in smaller numbers; so in 2013 the average values were $\overline{\mathbf{x}}=20.35 \mathrm{nimphs} / \mathrm{plant} / \mathrm{read}$ and $\overline{\mathbf{X}}=18.34$, respectively $\overline{\mathbf{X}}=47.65$ nimphs and $\overline{\mathbf{X}}=45.55$ adults for 2014 (Fig. 2).

A comparative study between the four varieties of tomatoes that have been reported all forms of green stink bugs N.viridula, revealed a greatest number of individuals in Oxheart variety ( $\overline{\mathbf{x}}>100.0$ ) (Fig.3). High values were recorded and variety Costoluto Fiorentino ( $\overline{\mathbf{x}}=55.66 ; 96.56)$. Mean values were reported in Sweet Baby variety (
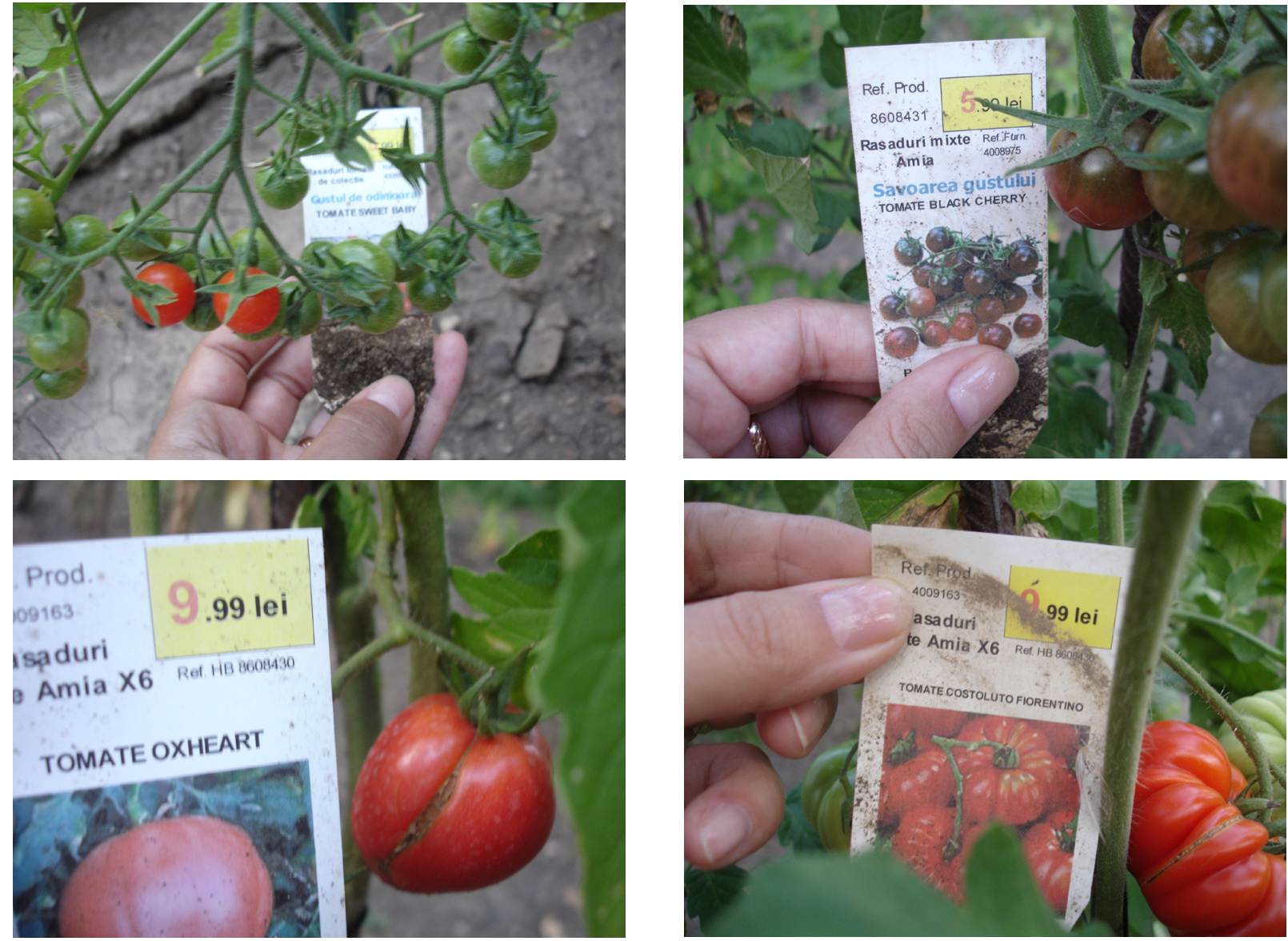

Fig. 1 The four varieties of tomatoes tested were purchased commercially: top left- variety of Sweet Baby; bottom left- variety of Oxheart, top right- Black Cherry and bottom right- Costoluto Fiorentino 
$\overline{\mathbf{X}}=47.33 ; 66.07)$. Less preferred have been shown to be the plants of the variety Black Cherry ( $\overline{\mathbf{x}}$ $=17.00$; 21.6) (Fig. 3).

In all varieties it can see that in 2014 the average value of the numbers of bed bugs was higher than previous year.
In green space only adults and nymphs were observed on follow ornamental plants: Syringa vulgaris, Lonicera japonica, Hibiscus sp. and Magnolia liliiflora (Fig. 4, Fig. 8. Fig, 9). Observations were made on several plants belonging to 30 botanical families.

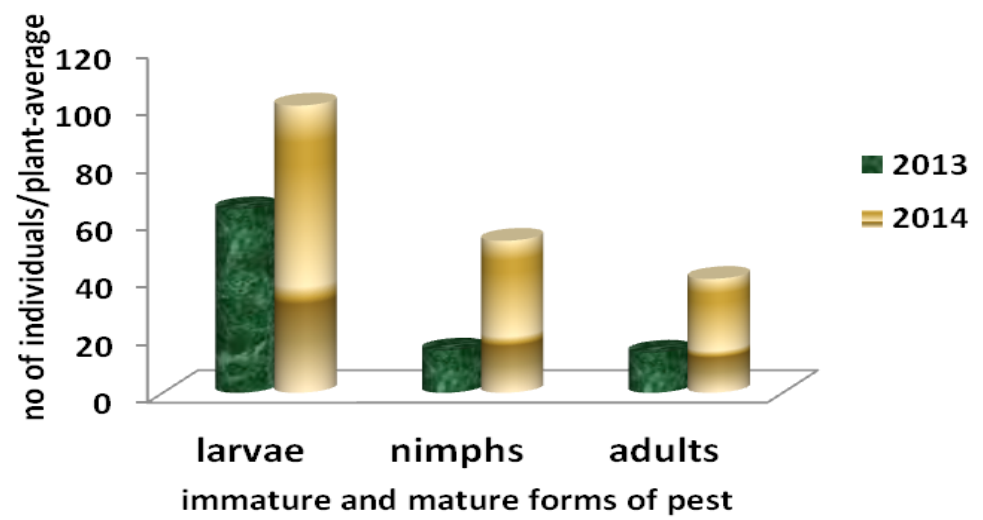

Fig. 2 Average number of individuals belonging different form of Nezara viridula, in experimental plots with tomatoes

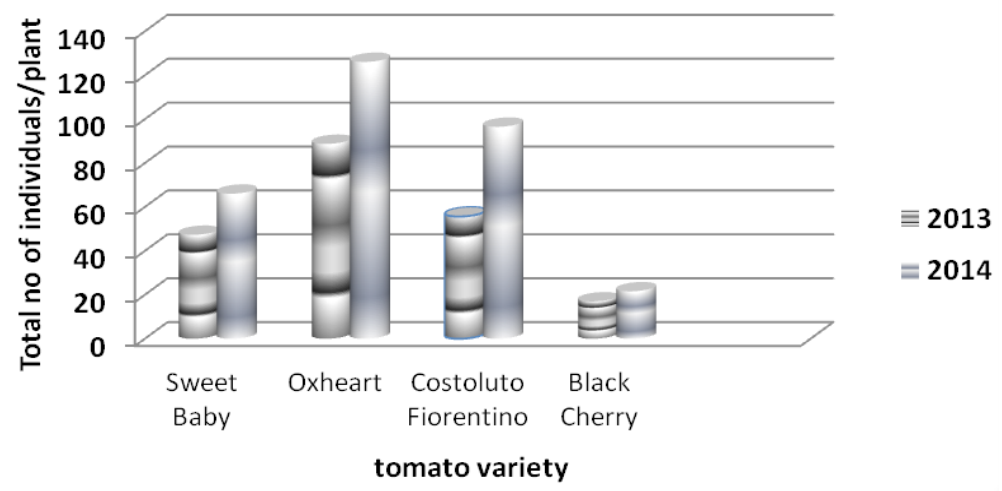

Fig. 3 Total number of $N$. viridula individuals on four tomato varieties

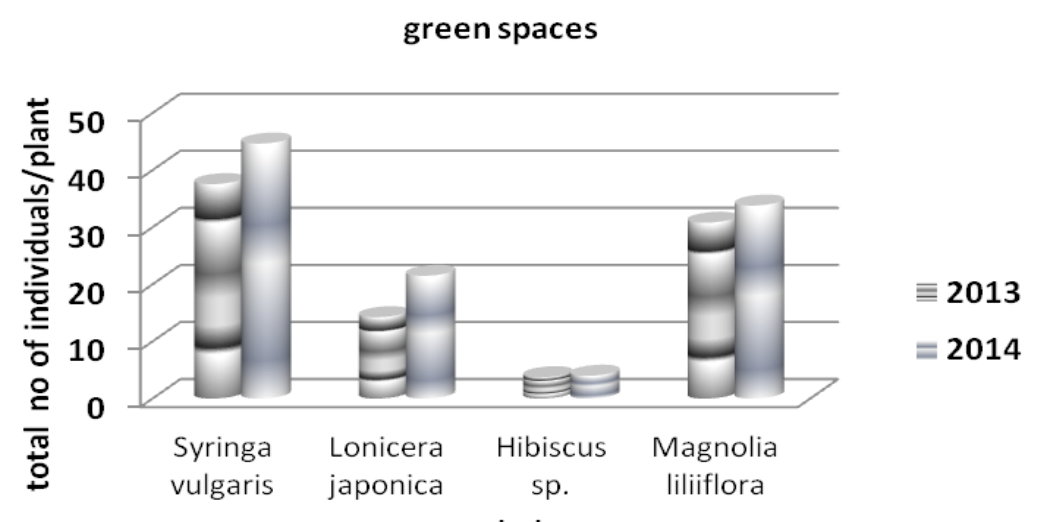

Fig. 4 Total number of $N$. viridula individuals on ornamental plants in green spaces 


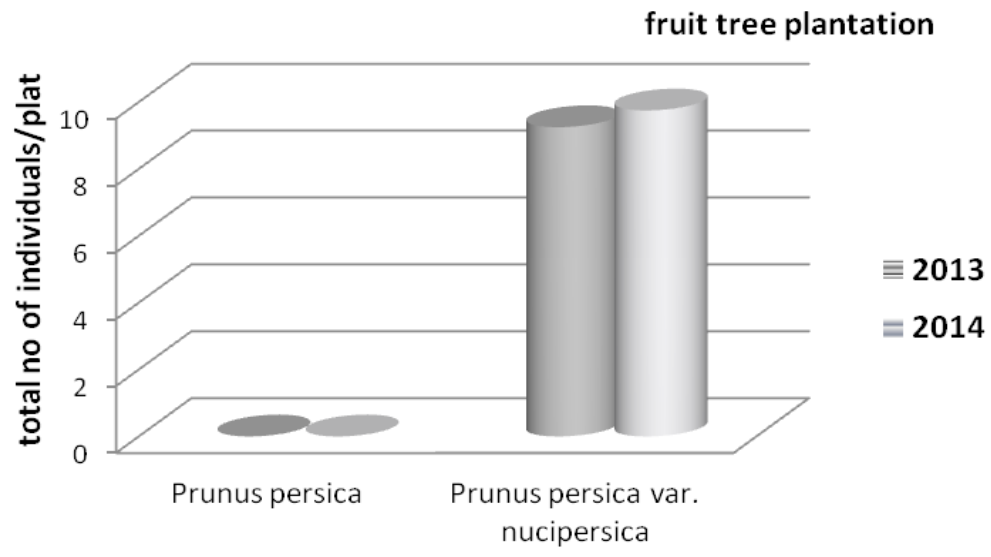

Fig. 5 Total number of $N$. viridula individuals on fruit tree plantation

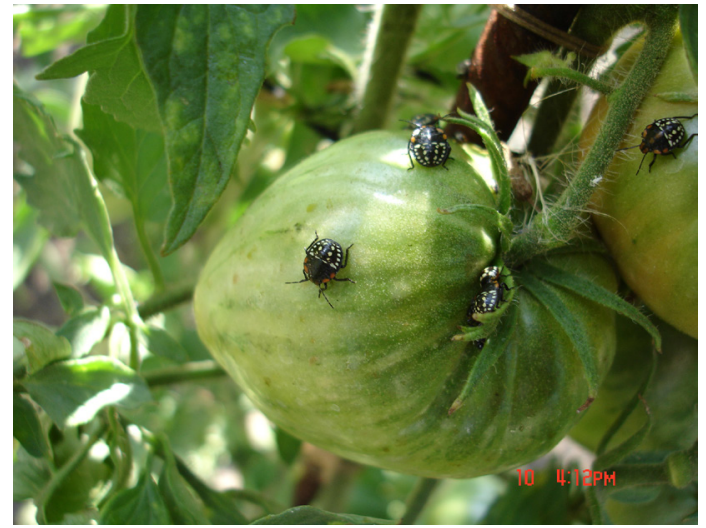

Fig. 6 Attacking larvae in green tomato fruits

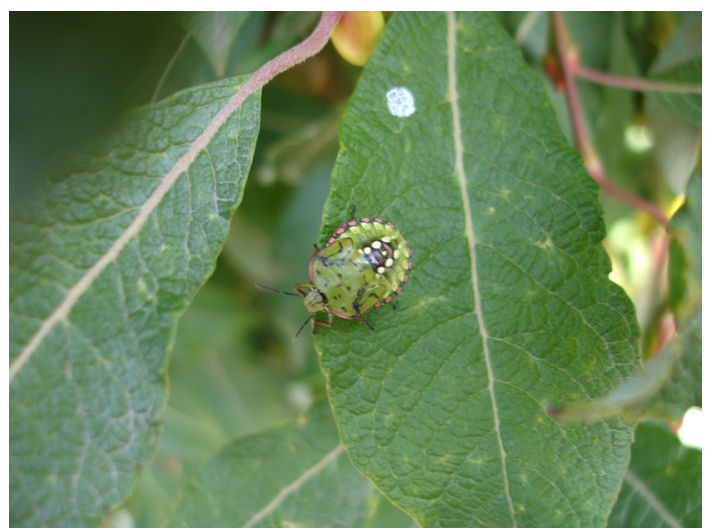

Fig. 8 Nimph on plant of Magnolia liliiflora

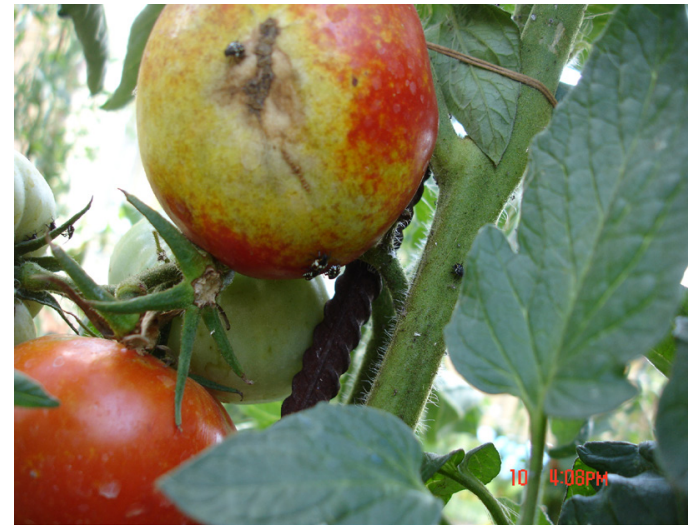

Fig. 7 Attacking larvae in red tomato fruits

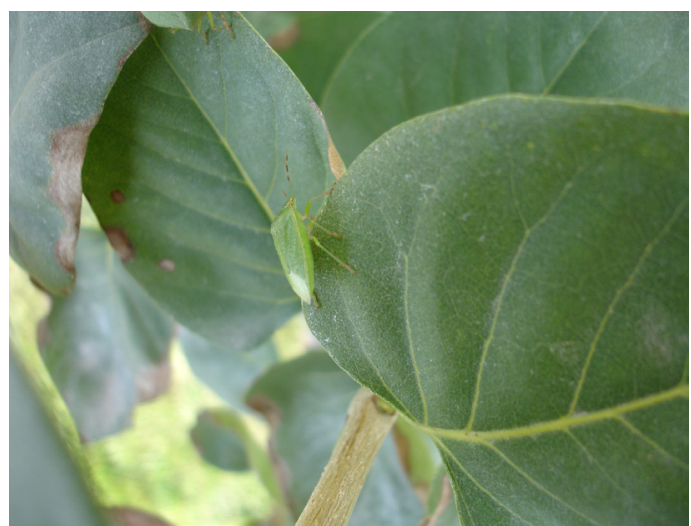

Fig. 9 Adult on leaves of Syringa vulgaris

Fig. 6, 7, 8, 9 Aspects of the attack produced by stink bug, Nezara viridula, on tomato plants and ornamentals

In terms of population level of the species $N$. viridula in green spaces it stands on this lilac and magnolia plants ( $\overline{\mathbf{x}}=37.56 ; 44.66$ adults/Syringa vulgaris and $\overline{\mathbf{x}}=30.8 ; 33.8$ nimphs/ Magnolia liliiflora.
Few adults were seen on leaves of Japanese honeysuckle and hibiscus ( $\overline{\mathbf{x}}=3.75 .8 ; 4$.0ind./ Lonicera japonica and $\overline{\mathbf{x}}=14.25 ; 21.5$ ind./Hibiscus sp.) (Fig. 4).

Values recorded in 2013 were in almost all host plants species lower compared to 2014, 
except for the species Hibiscus sp. where values were similarly.

Comparative study between Prunus persica and Prunus persica var. nucipersica (Fig. 5) made in fruit tree plantation has revealed that insect affected only the last one. Although on peach tree they found only 1 each adult/plant or none $(\overline{\mathbf{x}}$ $=0.00 ; 2.00)$ if compared with nectarine, $\overline{\mathbf{x}}=9.25$; 9.75 , we can say that the peach does not fit the preferences of the pest area.

There were no differences visible between the two years of observations, average values are very close.Direct observations on plants have shown that $N$. viridula affected all four varieties of tomatoes, especially on fruits, both green and mature stage. Adults, nimphs and larvae caused damage equally on tomatoes crops.

All types of insect forms development has been observed on tomato plants, such as eggs, larvae, nymphs and adults. All plants in the experimental group showed colonies of small larvae (dark) or larvae large solitary (dark with lighter dorsal points), nymphs (green with lighter points) and adults (green); some of plants have eggs groups (transparent white).

Only fruits were attacked in tomato plants; visibile damage were produced especially mature fruits (red fruits). The attacked fruits have many points yellowish joined forming large patches (Fig. 7). Ripe fruits were affected by transforming tissue but also by changing taste, could not be consumed due to the unpleasant smell and taste („,bedbug smell").

Green fruits were affected (Fig.6), too by bleaching tissue and dirty looking by appearance of spills or drops (dirty looking keeping in red fruits).

Ornamental plants were affected only in the leaf, by nymphs and adults of the species $N$. viridula (Fig. 8, Fig. 9). The infested leaves had whitish a few points higher and necrotic spots. Anyway, the plants were affected more qualitative by unpleasant smell.

Nectarine were affected only on the ripe fruit.

If we make an analysis of population level and aspect of plant injury can conclude that tomatoes are preferred of green stink bedbug. It seems that tomato plants gives conditions for development, feeding and breeding.

\section{CONCLUSION}

Invasive species is present both in agricultural areas and green spaces, on vegetable from gardens, fruit plantations and ornamental plants. Away, pest prefers vegetables from gardens and especially tomatoes. Most often attacks the tomato ripe fruit, but in the green fruit was observed. On ornamental plants were seen to stick only leaves, while in fruit trees they preferred fruit mature.

Since 2011, the population of this pest has increased worryingly, so requires consideration of strategies to control in future.

Acknowledgments. We thanks to relevant authorities from Timisoara that have allowed to made observation in the park Botanic.

\section{REFERENCES}

1. Capinera JL (2001). Handbook of vegetable pests. Academic Press, San Diego. 729 p.

2. Lye BH, Story RN, Wright VL (1988). Southern gree stink bug (Hemiptera:Pentatomidae) damage to fresh market tomatoes. J Ec. Entomol. 81: 190-194.

3. Musolin DL (2005). The the southern gree stink bug Nezara viridula (L.) expands its distribution range, not only in the UK-Newsl. Heter. Rec. Sch. (Het news).

4. Musolin DL (2012). Surviving winter: diapause syndrome in the southern gree stink bug Nezara viridula. Phisiol. Entomol. 37(4): 309-322.

5. Panizzi AR (2008). Southern green stink bug, Nezara viridula (L.) Hemiptera:Heteroptera: Pentatomidae). Enc. Entomol. 3471-3471.

6. Squitier JM (1997). Southern green stink bug Nezara viridula (Linnaeus.) (Insecta:Hemiptera:Pentatomidae). UFIFAS Extension, Univ. Florida. EENY-016(IN142).

7. Todd JW (1989). Ecology and behaviour of Nezara viridula. Ann. Rev. Entomol 34: 273-292.

8. Yukava J, Kiritani K, Gyoutoku N, Uechi N, Yamaguchi D, Kamitani S (2007). Distribution range shift of two allied species,Nezara viridula and N. Antennata (Hemiptera:Pentatomidae) in Japan, possibly due to global warming. Appl. Entomol. Zool. 42(2): 205-215. 